\title{
Avifauna em pequenas propriedades que visam o manejo florestal no Município de Fernandes Pinheiro, PR
}

\author{
Vânia Rossetto Marcelino ${ }^{1}$, Kelly Geronazzo Martins ${ }^{1}$, Afonso Figueiredo Filho ${ }^{1}$ \\ ${ }^{1}$ Universidade Estadual do Centro-Oeste, Campus de Irati, PR 153, km 07, Bairro Riozinho, CP 21, CEP 84.500-000, Irati, PR, Brasil
}

"Autor correspondente:
vania@irati.unicentro.br

Termos para indexação:

Floresta Ombrófila Mista

Fragmentação florestal

Bioindicador

Comunidade arbórea

Aves

Index terms:

Ombrophylous Mixed Forest

Forest fragmentation

Bioindicator

Tree community

Birds

Histórico do artigo:

Recebido em 29/05/2013

Aprovado em 04/03/2014

Publicado em 04/04/2014

doi: 10.4336/2014.pfb.34.77.542
Resumo - Objetivou-se com esse trabalho realizar um primeiro diagnóstico de aves locais em seis fragmentos de Floresta Ombrófila Mista, com métodos propícios a serem repetidos em períodos posteriores. A partir do monitoramento da avifauna em longo prazo, essa poderá ser usada como bioindicador local, principalmente em se tratando de áreas que deverão sofrer manejo futuro de espécies arbóreas. Em toda a localidade amostrada foram registradas 124 espécies, distribuídas em 41 famílias. Foi registrada a presença de quatro espécies constantes do Livro Vermelho da Fauna Ameaçada no Estado do Paraná: Polioptila lactea (balança-rabo-leitoso), Mesembrinibis cayennensis (coró-coró), Accipiter superciliosus (gavião-miudinho) e Leptasthenura striolata (grimpeirinho). Em seis fragmentos florestais, amostrados utilizando-se o método de trajetos-irregulares, foram registras 102 espécies. Também se procedeu à amostragem da vegetação arbórea por parcelas, registrando-se 92 espécies. As matrizes de Frequência Relativa da comunidade de aves silvestres e seu subgrupo de espécies especialistas florestais apresentaram correlação significativa com o Valor de Cobertura da comunidade arbórea (DAP $\geq 10 \mathrm{~cm})$.

\section{Avifauna on small farms aiming forest management in Fernandes Pinheiro city, Parana State, Brazil}

\begin{abstract}
This work aimed to carry out a first diagnosis of local birds, concentrating in six fragments of Ombrophylous Mixed Forest, using methods adequate to be repeated in subsequent periods. The assessment of birds on long-term may be used as local bioindicator, especially because these areas will be managed in the future. In the sampled area it was registered 124 species from 41 families. Four species listed in the Red Book of Threatened Fauna in the State of Paraná were recorded: Polioptila lactea (Creamy-bellied Gnatcatcher), Mesembrinibis cayennensis (Green Ibis), Accipiter superciliosus (Tiny Hawk) and Leptasthenura striolata (Striolated Tit-Spinetail). When the six forest fragments were assessed using the irregular transects method, it was registered 102 species. The trees survey, carried out by sample plots, resulting in 92 species. The Relative Frequency of wild bird community matrix and its sub-group of forest specialist birds presented significant correlation with the Coverage Value of the tree community $(\mathrm{DBH} \geq 10 \mathrm{~cm})$.
\end{abstract}




\section{Introdução}

Os remanescentes de Floresta Ombrófila Mista no Estado do Paraná se apresentam bastante fragmentados e degradados, a maioria em estágio inicial $(14,04 \%$ do original) e médio $(14,47 \%)$ de sucessão secundária, restando apenas $0,8 \%$ de florestas em estágio avançado de sucessão, praticamente inexistindo florestas primárias (Castella \& Britez, 2004).

Devido à grande heterogeneidade ambiental e de distribuição desses remanescentes, além das diferenças sócio-econômicas em todo o estado, estratégias de conservação apontadas para este ecossistema incluem planejamento político e ambiental regionais, estabelecendo áreas de preservação, recuperação e manejo (Castella \& Britez, 2004).

A fauna silvestre é um importante componente da floresta. Em um clássico trabalho de revisão de dados, Howe \& Smallwood (1982) concluíram que mais de $60 \%$ das plantas lenhosas em florestas temperadas são dispersas por vertebrados; em florestas neotropicais esse percentual fica entre 65 e $90 \%$, podendo ser até mais em alguns casos. Campassi (2006), em extensa revisão sobre as síndromes de dispersão em comunidades arbustivoarbóreas do Bioma Mata Atlântica, encontrou cerca de $77 \%$ das espécies de florestas ombrófilas e $70 \%$ das espécies de florestas estacionais sendo dispersas por vertebrados; mais da metade dessa proporção é realizada exclusivamente por aves.

A fauna é também um bioindicador do estado de conservação dos fragmentos florestais e outros ecossistemas. As aves silvestres são muito utilizadas como bioindicadores por ser um dos grupos taxonômicos mais bem estudados no país, com conhecimento sobre a biologia e a ecologia da maioria das espécies, além da facilidade de reconhecimento destas em campo, o que significa também economia de tempo e recursos financeiros. Grande parte delas é facilmente visualizada ou ouvida durante o dia e ocupam tanto ecossistemas terrestres quanto aquáticos e também todos os estratos de uma floresta. Em consequência dessa importância, buscou-se realizar um levantamento quali-quantitativo das aves silvestres em pequenas propriedades rurais que mantêm seus fragmentos florestais total ou parcialmente protegidos.

O presente estudo faz parte do projeto "Estratégias para o manejo florestal sustentável em pequenas propriedades rurais no Centro-Sul do Paraná, Brasil", cujo objetivo é testar alternativas de manejo para a obtenção de produtos florestais madeireiros e nãomadeireiros em propriedades consideradas pequenas (até 64 ha). Futuramente, os bioindicadores, como a avifauna e a comunidade arbórea, estudados em termos de dinâmica de comunidades, poderão ajudar a entender se e em que intensidade o manejo florestal atua nas mudanças da biodiversidade.

Neste contexto, os objetivos da presente pesquisa foram: a) realizar a descrição qualitativa diagnóstica da avifauna de uma localidade rural para futuro monitoramento; b) realizar a descrição quantitativa diagnóstica da avifauna de seis fragmentos florestais amostrados para futuro monitoramento; c) usar a avifauna como ferramenta bioindicadora do estado de conservação dos locais amostrados; d) testar se existe correlação entre as espécies de aves e as espécies arbóreas amostradas nos fragmentos.

\section{Material e métodos}

\section{Área de estudo}

A área de estudo é a localidade rural denominada Assungui (25³2'29.64'S, 50³3'44.58'W), região de cabeceiras do Rio Imbituvão, no Município de Fernandes Pinheiro, PR. O clima na localidade pode ser classificado como Temperado ou do tipo $\mathrm{Cfb}$ (de acordo com o Sistema Internacional de Köppen), conforme observado nas Cartas Climáticas do Paraná (Caviglione et al., 2000). A formação vegetal original na área estudada é a Floresta Ombrófila Mista, nas variações Aluvial e Montana, segundo a classificação sugerida por Veloso et al. (1991).

Levantamentos florísticos e fitossociológicos foram realizados (Figueiredo Filho et al., 2013) em 27 fragmentos florestais da localidade, encontrando-se 106 espécies (DAP $\geq 10 \mathrm{~cm}$ ), sendo que 59,3\% dos fragmentos estão em estágio inicial de sucessão, 18,5\% em estágio secundário, $11,1 \%$ em estágio secundário/avançado e apenas $11,1 \%$ em estágio avançado de sucessão.

Adotou-se os critérios de classificação de Castella \& Britez (2004) para caracterizá-los quanto à qualidade estrutural da vegetação nos estudos de avifauna. Os seis fragmentos selecionados para estudo da avifauna podem ser considerados como em estágios secundário e avançado de sucessão, segundo esta classificação.

Os fragmentos em que se realizou o levantamento quantitativo da avifauna são compostos por vegetação secundária por simplificação, onde não houve corte raso, 
mas retirada seletiva de madeira. Como cada fragmento pertence a um proprietário, é esperado que a quantidade, tamanho e espécies de árvores retiradas sejam diferentes entre eles.

Os tamanhos e estágio de sucessão secundária (segundo classificação proposta por Castella \& Britez, 2004) dos fragmentos estudados encontram-se listados na Tabela 1. Todos os fragmentos fazem fronteira com áreas agrícolas, mas há áreas contínuas a outros fragmentos, separados apenas por uma estrada rural ou um rio. A exceção é o fragmento 5 , que é todo rodeado por outros fragmentos bosqueados para criação de bovinos e equinos.

Tabela 1. Tamanho e estágio de sucessão secundária dos fragmentos florestais estudados na localidade Assungui, Fernandes Pinheiro, PR.

\begin{tabular}{ccc}
\hline $\begin{array}{c}\text { Número do } \\
\text { fragmento } \\
\text { florestal }\end{array}$ & $\begin{array}{c}\text { Área do } \\
\text { fragmento } \\
\text { florestal } \\
\text { (em hectares) }\end{array}$ & $\begin{array}{c}\text { Estágio de } \\
\text { sucessão } \\
\text { secundária }\end{array}$ \\
\hline 1 & 43,47 & médio \\
2 & 26,09 & avançado \\
3 & 27,15 & avançado \\
4 & 21,62 & médio \\
5 & 12,12 & médio \\
6 & 18,43 & avançado \\
\hline
\end{tabular}

\section{Métodos de levantamento da avifauna}

A primeira visita de reconhecimento à área de estudo foi realizada em setembro de 2010, quando foram efetuadas algumas observações aleatórias para levantamento qualitativo. Durante os deslocamentos posteriores entre as propriedades e seus arredores foram registradas espécies não captadas pelo método quantitativo dos trajetos-irregulares, o que resultou em uma lista mais completa das aves locais.

Para fins de discussão do status de conservação das espécies, consultou-se o "Livro Vermelho da Fauna Ameaçada no Estado do Paraná (Mikich \& Bérnils, 2004), o qual é considerado como lista oficial do Estado.

As espécies foram classificadas de acordo com o hábitat preferencial para fins de discussão da qualidade dos fragmentos estudados. As categorias propostas são: Especialista Forestal (E); Campestre ou Aquática (C); e Generalista (G). Espécies consideradas especialistas florestais são aquelas que preferem habitar florestas, embora algumas possam eventualmente ser observadas em bordas, capoeiras e mesmo em áreas abertas ou semiabertas próximas a florestas; são boas indicadoras da qualidade estrutural de florestas. Espécies classificadas como campestres ou aquáticas são aquelas normalmente observadas apenas em campo aberto ou muito próximas de corpos-d'água, estando fora desses ambientes apenas quando se deslocam entre locais de forrageamento, nidificação ou dormitórios, ou eventualmente quando fogem de predadores; são aves raramente encontradas em ambientes florestais bem estruturados. Espécies generalistas são aquelas que habitam diversos tipos de ambientes, sem preferência por cobertura vegetal específica. Para a classificação das espécies em tais categorias, consultou-se as referências Anjos et al. (1997) e Sick (1997).

$\mathrm{O}$ método de amostragem quantitativa consistiu em trajetos-irregulares (Bibby et al., 1993). A escolha deste método se deu pelas vantagens de seu uso em vista às circunstâncias da pesquisa: grandes áreas heterogêneas com acesso limitado. Segundo Bibby et al. (1993), quando o observador caminha por certo tempo, é possível cobrir uma área maior do que por outros métodos mais elaborados, como ponto-fixo e captura com rede-de-neblina, levando-se em conta as restrições de horas de trabalho e recursos para pesquisa em muitos casos; as rotas dos trajetos são percorridas uma ou poucas vezes, usando o tempo disponível para incluir rotas diferentes. Levando-se em conta a equipe disponível e os objetivos do trabalho, não houve a possibilidade de um levantamento exaustivo das espécies, assim o método de captura com redes-de-neblina não foi utilizado.

Os trajetos foram percorridos entre março e maio de 2012, setembro e dezembro de 2012 e março e abril de 2013. Os horários de observação se restringiram às manhãs, procurando otimizar o tempo disponível para pesquisa e levando-se em conta que as aves aqui são consideradas bioindicadores, não sendo objetivo do trabalho o levantamento completo das espécies locais. O horário de início e término dos trajetos dependeu da época do ano, de acordo com o nascer do sol até a hora mais quente no meio da manhã, em que as aves já ficavam bastante quietas e pouco se movimentavam; esse horário variou entre 6:35 e 10:30. Em cada fragmento foram realizadas seis horas de observação, gerando um total de 36 horas. 
Durante os percursos, todos os indivíduos identificados por meio de registros visuais e/ou sonoros foram contabilizados, desde que avistados dentro dos fragmentos florestais. A quantidade de horas de observação foi utilizada como unidade amostral. A visualização foi realizada com auxílio de binóculos Nikon Monarch 10x42, quando necessário. Os registros sonoros foram gravados quando possível e necessária a confirmação posterior da espécie, por comparação com arquivos sonoros digitais. O equipamento utilizado foi um gravador analógico Marantz PMD222 com microfone Sennheiser acoplado.

Para fins de comparação entre os fragmentos, foi calculada a Frequência Relativa (FR) de cada espécie para cada um dos fragmentos. AFR é dada pelo número de indivíduos (Ni) registrados na espécie $i$ em relação ao número de horas de observação. A nomenclatura científica e vernácula das aves e sua ordem de apresentação nas tabelas segue o proposto pelo Comitê Brasileiro de Registros Ornitológicos (2014).

\section{Método de levantamento de espécies arbóreas}

O levantamento de espécies arbóreas utilizado neste trabalho foi apresentado em Figueiredo Filho et al.(2013), onde foram considerados todos os indivíduos com diâmetro a $1,30 \mathrm{~m}$ do solo igual ou superior a $10 \mathrm{~cm}$.

\section{Análise quantitativa}

Para explorar os padrões de riqueza dos fragmentos estudados foram construídas curvas de rarefação. Este método consiste em calcular o número esperado de espécies em cada amostra para um tamanho de amostra padrão (Gotelli \& Colwell, 2001). Concomitantemente, para estimar a riqueza de espécies por fragmento foi utilizado o Bootstrap com 500 permutações. Esta técnica consiste em estimar a riqueza total utilizando dados de todas as espécies, não se restringindo às espécies raras (Gotelli \& Colwell, 2011). Tais cálculos foram efetuados com o auxílio do programa Estimates 9.1 (Cowell, 2013).

Buscando averiguar possíveis agrupamentos entre os fragmentos florestais amostrados neste estudo, foram efetuadas três análises de agrupamento hierárquico. Na primeira, foi usada a matriz de Frequência Relativa das espécies de aves, considerando toda a comunidade amostrada através do método de trajetos-irregulares. Neste agrupamento, para se determinar a distância, foi usada a medida de similaridade Relative Sorensen e o método de ligação compatível, no caso Group Average (McCune \& James, 2002). O segundo agrupamento foi efetuado com a matriz de Frequência Relativa das espécies de aves especialistas florestais (subgrupo da comunidade amostrada durante os trajetos). O cálculo da distância foi efetuado pela medida de similaridade Jaccard e o método de ligação compatível Group Average (McCune \& James, 2002). O último agrupamento foi gerado mediante a matriz de Valor de Cobertura das espécies arbóreas, em que a distância foi determinada pela medida de similaridade Relative Sorensen e o método de ligação compatível Group Average (McCune \& James, 2002).

O coeficiente de correlação cofenética, que é a medida do grau de deformação provocado pela construção do dendrograma, foi calculado para verificar a distorção entre a matriz original e a gerada para a construção do dendrograma. De forma geral, coeficientes cofenéticos maiores que 0,8 são considerados apropriados (Legendre \& Legendre, 1998).

Para testar a hipótese de que existe correlação entre a comunidade de aves e a de árvores nos fragmentos amostrados, dois testes de Mantel, com 999 permutações, foram efetuados. O primeiro correlacionou a matriz de Frequência Relativa de aves com a de Valor de Cobertura de espécies arbóreas. O segundo teste avaliou se existe correlação entre a matriz de Valor de Cobertura de espécies arbóreas e a matriz de Frequência Relativa de aves especialistas florestais. Os índices de diversidade e equitabilidade de Shanon e Evennes, respectivamente, também foram calculados para as comunidades de aves e árvores amostradas. Estes cálculos foram efetuados com o auxílio do programa PC-ORD versão 6.0 (McCune \& James, 2002).

\section{Resultados e discussão}

\section{Análise qualitativa da avifauna}

Foram registradas 124 espécies de aves, distribuídas em 41 famílias (Tabela 2). Destas, 102 espécies foram registradas durante os trajetos-irregulares, e as demais foram registradas ao acaso nas propriedades estudadas ou em outros locais do povoado, durante visitas esporádicas ou deslocamento entre um trajeto e outro. 
Tabela 2. Famílias e espécies de aves registradas na localidade Assungui, Fernandes Pinheiro, PR, e respectiva classificação quanto ao hábito (hábitat preferencial): $\mathrm{E}=$ Especialista Florestal; $\mathrm{C}=$ Campestre ou Aquática; $\mathrm{G}=$ Generalista.

\begin{tabular}{|c|c|c|}
\hline Nome do táxon & Nome popular & Hábito \\
\hline \multicolumn{3}{|l|}{ Tinamidae Gray, 1840} \\
\hline $\begin{array}{l}\text { Crypturellus obsoletus } \\
\text { (Temminck, 1815) }\end{array}$ & inhambuguaçu & E \\
\hline $\begin{array}{l}\text { Crypturellus tataupa } \\
\text { (Temminck, 1815) }\end{array}$ & inhambu-chintã & G \\
\hline $\begin{array}{l}\text { Rhynchotus rufescens } \\
\text { (Temminck, 1815) }\end{array}$ & perdiz & $\mathrm{C}$ \\
\hline
\end{tabular}

Anatidae Leach, 1820

Amazonetta brasiliensis

(Gmelin, 1789)

pé-vermelho $\quad \mathrm{C}$

Cracidae Rafinesque, 1815

Penelope obscura Temminck, 1815 jacuaçu

G

Ardeidae Leach, 1820

Syrigma sibilatrix, (Temminck, 1824) maria-faceira C

Threskiornithidae Poche, 1904

Mesembrinibis cayennensis

(Gmelin, 1789)

Theristicus caudatus

(Boddaert, 1783)

curicaca $\quad \mathrm{C}$

\section{Cathartidae Lafresnaye, 1839}

Coragyps atratus (Bechstein, 1793)

Accipitridae Vigors, 1824

Accipiter superciliosus

(Linnaeus, 1766)

Rupornis magnirostris

(Gmelin, 1788)

Geranoaetus albicaudatus

(Vieillot, 1816)

Rallidae Rafinesque, 1815

\begin{tabular}{|c|c|c|}
\hline Aramides saracura (Spix, 1825) & saracura-do-mato & $\mathrm{G}$ \\
\hline $\begin{array}{l}\text { Gallinula galeata } \\
\text { (Lichtenstein,1818) }\end{array}$ & $\begin{array}{l}\text { frango-d'água- } \\
\text { comum }\end{array}$ & $\mathrm{C}$ \\
\hline \multicolumn{3}{|l|}{ Charadriidae Leach, 1820} \\
\hline Vanellus chilensis (Molina, 1782) & quero-quero & $\mathrm{C}$ \\
\hline \multicolumn{3}{|l|}{$\begin{array}{l}\text { Jacanidae Chenu \& Des Murs, } \\
1854\end{array}$} \\
\hline Jacana jacana (Linnaeus, 1766) & jaçanã & $\mathrm{C}$ \\
\hline \multicolumn{3}{|l|}{ Columbidae Leach, 1820} \\
\hline $\begin{array}{l}\text { Columbina talpacoti } \\
\text { (Temminck, 1811) }\end{array}$ & rolinha-roxa & $\mathrm{C}$ \\
\hline $\begin{array}{l}\text { Columbina squammata } \\
\text { (Lesson, 1831) }\end{array}$ & fogo-apagou & $\mathrm{C}$ \\
\hline Columba livia Gmelin, 1789 & pombo-doméstico & $\mathrm{C}$ \\
\hline $\begin{array}{l}\text { Patagioenas picazuro } \\
\text { (Temminck, 1813) }\end{array}$ & pombão & $\mathrm{G}$ \\
\hline $\begin{array}{l}\text { Zenaida auriculata } \\
\text { (Des Murs, 1847) }\end{array}$ & pomba-de-bando & $\mathrm{C}$ \\
\hline Leptotila verreauxi Bonaparte, 1855 & juriti-pupu & $\mathrm{G}$ \\
\hline $\begin{array}{l}\text { Leptotila rufaxilla (Richard \& } \\
\text { Bernard, 1792) }\end{array}$ & juriti-gemedeira & $\mathrm{G}$ \\
\hline
\end{tabular}

Tabela 2. Continuação.

\begin{tabular}{|c|c|c|}
\hline Nome do táxon & Nome popular & Hábito \\
\hline \multicolumn{3}{|l|}{ Cuculidae Leach, 1820} \\
\hline Piaya cayana (Linnaeus, 1766) & alma-de-gato & G \\
\hline Crotophaga ani Linnaeus, 1758 & anu-preto & $\mathrm{C}$ \\
\hline Guira guira (Gmelin, 1788) & anu-branco & $\mathrm{C}$ \\
\hline Tapera naevia (Linnaeus, 1766) & saci & $\mathrm{C}$ \\
\hline \multicolumn{3}{|l|}{ Trogonidae Lesson, 1828} \\
\hline Trogon surrucura Vieillot, 1817 & surucuá-variado & $\mathrm{G}$ \\
\hline \multicolumn{3}{|l|}{ Alcedinidae Rafinesque, 1815} \\
\hline $\begin{array}{l}\text { Megaceryle torquata (Linnaeus, } \\
1766 \text { ) }\end{array}$ & $\begin{array}{l}\text { martim-pescador- } \\
\text { grande }\end{array}$ & $\mathrm{C}$ \\
\hline \multicolumn{3}{|l|}{ Bucconidae Horsfield, 1821} \\
\hline Nystalus chacuru (Vieillot, 1816) & joão-bobo & $\mathrm{C}$ \\
\hline \multicolumn{3}{|l|}{ Ramphastidae Vigors, 1825} \\
\hline $\begin{array}{l}\text { Ramphastos dicolorus Linnaeus, } \\
1766\end{array}$ & $\begin{array}{l}\text { tucano-de-bico- } \\
\text { verde }\end{array}$ & $\mathrm{E}$ \\
\hline \multicolumn{3}{|l|}{ Picidae Leach, 1820} \\
\hline $\begin{array}{l}\text { Picumnus temminckii Lafresnaye, } \\
1845\end{array}$ & $\begin{array}{l}\text { pica-pau-anão- } \\
\text { de-coleira }\end{array}$ & $\mathrm{G}$ \\
\hline Melanerpes candidus (Otto, 1796) & pica-pau-branco & $\mathrm{G}$ \\
\hline $\begin{array}{l}\text { Veniliornis spilogaster } \\
\text { (Wagler, 1827) }\end{array}$ & $\begin{array}{l}\text { picapauzinho- } \\
\text { verde-carijó }\end{array}$ & G \\
\hline $\begin{array}{l}\text { Piculus aurulentus } \\
\text { (Temminck, 1821) }\end{array}$ & pica-pau-dourado & $\mathrm{E}$ \\
\hline $\begin{array}{l}\text { Colaptes melanochloros } \\
\text { (Gmelin, 1788) }\end{array}$ & $\begin{array}{l}\text { pica-pau-verde- } \\
\text { barrado }\end{array}$ & $\mathrm{G}$ \\
\hline $\begin{array}{l}\text { Colaptes campestris } \\
\text { (Vieillot, 1818) }\end{array}$ & $\begin{array}{l}\text { pica-pau-do- } \\
\text { campo }\end{array}$ & $\mathrm{C}$ \\
\hline $\begin{array}{l}\text { Dryocopus lineatus } \\
\text { (Linnaeus, 1766) }\end{array}$ & $\begin{array}{l}\text { pica-pau-de- } \\
\text { banda-branca }\end{array}$ & G \\
\hline $\begin{array}{l}\text { Campephilus robustus } \\
\text { (Lichtenstein, 1818) }\end{array}$ & pica-pau-rei & G \\
\hline \multicolumn{3}{|l|}{ Falconidae Leach, 1820} \\
\hline Caracara plancus (Miller, 1777) & caracará & $\mathrm{G}$ \\
\hline $\begin{array}{l}\text { Milvago chimachima (Vieillot, } \\
\text { 1816) }\end{array}$ & carrapateiro & $\mathrm{G}$ \\
\hline $\begin{array}{l}\text { Herpetotheres cachinnans } \\
\text { (Linnaeus, 1758) }\end{array}$ & acauã & $\mathrm{G}$ \\
\hline Falco sparverius Linnaeus, 1758 & quiriquiri & $\mathrm{C}$ \\
\hline \multicolumn{3}{|l|}{ Psittacidae Rafinesque, 1815} \\
\hline Pyrrhura frontalis (Vieillot, 1817) & $\begin{array}{l}\text { tiriba-de-testa- } \\
\text { vermelha }\end{array}$ & $\mathrm{E}$ \\
\hline Pionus maximiliani (Kuhl, 1820) & maitaca-verde & G \\
\hline \multicolumn{3}{|l|}{ Thamnophilidae Swainson, 1824} \\
\hline $\begin{array}{l}\text { Dysithamnus mentalis (Temminck, } \\
1823 \text { ) }\end{array}$ & choquinha-lisa & $\mathrm{E}$ \\
\hline $\begin{array}{l}\text { Thamnophilus caerulescens } \\
\text { Vieillot, } 1816\end{array}$ & choca-da-mata & $\mathrm{G}$ \\
\hline $\begin{array}{l}\text { Hypoedaleus guttatus (Vieillot, } \\
\text { 1816) }\end{array}$ & chocão-carijó & $\mathrm{E}$ \\
\hline $\begin{array}{l}\text { Drymophila malura }(\text { Temminck, } \\
1825)\end{array}$ & choquinha-carijó & $\mathrm{E}$ \\
\hline
\end{tabular}


Tabela 2. Continuação.

\begin{tabular}{|c|c|c|}
\hline Nome do Táxon & Nome popular & Hábito \\
\hline \multicolumn{3}{|l|}{$\begin{array}{l}\text { Conopophagidae Sclater \& } \\
\text { Salvin, } 1873\end{array}$} \\
\hline Conopophaga lineata (Wied, 1831) & chupa-dente & G \\
\hline \multicolumn{3}{|l|}{ Formicariidae Gray, 1840} \\
\hline $\begin{array}{l}\text { Chamaeza campanisona } \\
\text { (Lichtenstein, 1823) }\end{array}$ & $\begin{array}{l}\text { tovaca- } \\
\text { campainha }\end{array}$ & $\mathrm{E}$ \\
\hline \multicolumn{3}{|l|}{ Scleruridae Swainson, 1827} \\
\hline Sclerurus scansor (Ménétriès, 1835) & vira-folha & $\mathrm{E}$ \\
\hline \multicolumn{3}{|l|}{ Dendrocolaptidae Gray, 1840} \\
\hline $\begin{array}{l}\text { Sittasomus griseicapillus (Vieillot, } \\
\text { 1818) }\end{array}$ & arapaçu-verde & $\mathrm{E}$ \\
\hline $\begin{array}{l}\text { Lepidocolaptes squamatus } \\
\text { (Lichtenstein, 1822) }\end{array}$ & $\begin{array}{l}\text { arapaçu- } \\
\text { escamado }\end{array}$ & $\mathrm{E}$ \\
\hline $\begin{array}{l}\text { Lepidocolaptes falcinellus } \\
\text { (Cabanis \& Heine, 1859) }\end{array}$ & $\begin{array}{l}\text { arapaçu- } \\
\text { escamado-do-sul }\end{array}$ & $\mathrm{E}$ \\
\hline $\begin{array}{l}\text { Dendrocolaptes platyrostris Spix, } \\
1825\end{array}$ & arapaçu-grande & G \\
\hline $\begin{array}{l}\text { Xiphocolaptes albicollis (Vieillot, } \\
1818 \text { ) }\end{array}$ & $\begin{array}{l}\text { arapaçu-de- } \\
\text { garganta-branca }\end{array}$ & $\mathrm{E}$ \\
\hline \multicolumn{3}{|l|}{ Furnariidae Gray, 1840} \\
\hline Furnarius rufus (Gmelin, 1788) & joão-de-barro & $\mathrm{C}$ \\
\hline $\begin{array}{l}\text { Lochmias nematura (Lichtenstein, } \\
1823 \text { ) }\end{array}$ & joão-porca & G \\
\hline Philydor rufum (Vieillot, 1818) & $\begin{array}{l}\text { limpa-folha-de- } \\
\text { testa-baia }\end{array}$ & $\mathrm{E}$ \\
\hline $\begin{array}{l}\text { Heliobletus contaminatus } \\
\text { Berlepsch, } 1885\end{array}$ & trepadorzinho & $\mathrm{E}$ \\
\hline Leptasthenura striolata (Pelzeln, 1856) & grimpeirinho & $\mathrm{E}$ \\
\hline $\begin{array}{l}\text { Leptasthenura setaria (Temminck, } \\
1824)\end{array}$ & grimpeiro & $\mathrm{E}$ \\
\hline $\begin{array}{l}\text { Synallaxis cinerascens Temminck, } \\
1823\end{array}$ & pi-puí & $\mathrm{E}$ \\
\hline Synallaxis spixi Sclater, 1856 & joão-teneném & G \\
\hline \multicolumn{3}{|l|}{ Pipridae Rafinesque, 1815} \\
\hline $\begin{array}{l}\text { Chiroxiphia caudata (Shaw \& } \\
\text { Nodder, 1793) }\end{array}$ & tangará & G \\
\hline \multicolumn{3}{|l|}{ Tityridae Gray, 1840} \\
\hline Tityra inquisitor (Lichtenstein, 1823) & $\begin{array}{l}\text { anambé-branco-de- } \\
\text { bochecha-parda }\end{array}$ & G \\
\hline $\begin{array}{l}\text { Pachyramphus castaneus (Jardine } \\
\text { \& Selby, 1827) }\end{array}$ & caneleiro & G \\
\hline $\begin{array}{l}\text { Pachyramphus validus } \\
\text { (Lichtenstein, 1823) }\end{array}$ & $\begin{array}{l}\text { caneleiro-de- } \\
\text { chapéu-preto }\end{array}$ & G \\
\hline \multicolumn{3}{|l|}{ Platyrinchidae Bonaparte, 1854} \\
\hline Platyrinchus mystaceus Vieillot, 1818 & patinho & $\mathrm{E}$ \\
\hline \multicolumn{3}{|l|}{ Rhynchocyclidae Berlepsch, 1907} \\
\hline Mionectes rufiventris Cabanis, 1846 & $\begin{array}{l}\text { abre-asa-de- } \\
\text { cabeca-cinza }\end{array}$ & $\mathrm{E}$ \\
\hline $\begin{array}{l}\text { Phylloscartes ventralis (Temminck, } \\
\text { 1824) }\end{array}$ & $\begin{array}{l}\text { borboletinha-do- } \\
\text { mato }\end{array}$ & G \\
\hline $\begin{array}{l}\text { Tolmomyias sulphurescens (Spix, } \\
\text { 1825) }\end{array}$ & $\begin{array}{l}\text { bico-chato-de- } \\
\text { orelha-preta }\end{array}$ & G \\
\hline $\begin{array}{l}\text { Poecilotriccus plumbeiceps } \\
\text { (Lafresnaye, 1846) }\end{array}$ & tororó & G \\
\hline Myiornis auricularis (Vieillot, 1818) & miudinho & $\mathrm{E}$ \\
\hline
\end{tabular}

Tabela 2. Continuação.

\begin{tabular}{|c|c|c|}
\hline Nome do Táxon & Nome popular & Hábito \\
\hline \multicolumn{3}{|l|}{ Tyrannidae Vigors, 1825} \\
\hline $\begin{array}{l}\text { Camptostoma obsoletum } \\
\text { (Temminck, 1824) }\end{array}$ & risadinha & G \\
\hline Elaenia flavogaster (Thunberg, 1822) & $\begin{array}{l}\text { guaracava-de- } \\
\text { barriga-amarela }\end{array}$ & G \\
\hline Elaenia parvirostris Pelzeln, 1868 & $\begin{array}{l}\text { guaracava-de- } \\
\text { bico-curto }\end{array}$ & G \\
\hline $\begin{array}{l}\text { Capsiempis flaveola (Lichtenstein, } \\
1823 \text { ) }\end{array}$ & $\begin{array}{l}\text { marianinha- } \\
\text { amarela }\end{array}$ & G \\
\hline $\begin{array}{l}\text { Phyllomyias virescens (Temminck, } \\
\text { 1824) }\end{array}$ & $\begin{array}{l}\text { piolhinho- } \\
\text { verdoso }\end{array}$ & G \\
\hline $\begin{array}{l}\text { Phyllomyias fasciatus (Thunberg, } \\
\text { 1822) }\end{array}$ & piolhinho & G \\
\hline $\begin{array}{l}\text { Pitangus sulphuratus (Linnaeus, } \\
\text { 1766) }\end{array}$ & bem-te-vi & G \\
\hline $\begin{array}{l}\text { Myiodynastes maculatus (Statius } \\
\text { Muller, 1776) }\end{array}$ & bem-te-vi-rajado & G \\
\hline $\begin{array}{l}\text { Megarynchus pitangua (Linnaeus, } \\
\text { 1766) }\end{array}$ & neinei & G \\
\hline $\begin{array}{l}\text { Tyrannus melancholicus Vieillot, } \\
1819\end{array}$ & suiriri & G \\
\hline Tyrannus savana Vieillot, 1808 & tesourinha & G \\
\hline Lathrotriccus euleri (Cabanis, 1868) & enferrujado & G \\
\hline \multicolumn{3}{|l|}{ Vireonidae Swainson, 1837} \\
\hline Cyclarhis gujanensis (Gmelin, 1789) & pitiguari & G \\
\hline Vireo chivi (Vieillot, 1817) & juruviara & G \\
\hline \multicolumn{3}{|l|}{ Corvidae Leach, 1820} \\
\hline $\begin{array}{l}\text { Cyanocorax caeruleus (Vieillot, } \\
1818 \text { ) }\end{array}$ & gralha-azul & $\mathrm{E}$ \\
\hline $\begin{array}{l}\text { Cyanocorax chrysops (Vieillot, } \\
1818 \text { ) }\end{array}$ & gralha-picaça & $\mathrm{G}$ \\
\hline \multicolumn{3}{|l|}{ Troglodytidae Swainson, 1831} \\
\hline $\begin{array}{l}\text { Troglodytes musculus Naumann, } \\
1823\end{array}$ & corruíra & G \\
\hline
\end{tabular}

\section{Polioptilidae Baird, 1858}

Polioptila lactea Sharpe, 1885

balança-raboleitoso

G

\section{Turdidae Rafinesque, 1815}

Turdus leucomelas Vieillot, 1818 sabiá-barranco G

Turdus rufiventris Vieillot, 1818 sabiá-laranjeira G

Turdus amaurochalinus Cabanis, sabiá-poca G 1850

Turdus albicollis Vieillot, 1818 sabiá-coleira E

\section{Mimidae Bonaparte, 1853}

Mimus saturninus (Lichtenstein, 1823) sabiá-do-campo

$\mathrm{C}$

Passerellidae Cabanis \& Heine,

1850

Zonotrichia capensis (Statius

Muller, 1776)

tico-tico

G 
Tabela 2. Continuação.

\begin{tabular}{|c|c|c|}
\hline Nome do Táxon & Nome popular & Hábito \\
\hline \multicolumn{3}{|l|}{$\begin{array}{l}\text { Parulidae Wetmore, Friedmann, } \\
\text { Lincoln, Miller, Peters, van } \\
\text { Rossem, Van Tyne \& Zimmer } 1947\end{array}$} \\
\hline Setophaga pitiayumi (Vieillot, 1817) & mariquita & G \\
\hline Basileuterus culicivorus (Deppe, 1830) & pula-pula & $\mathrm{G}$ \\
\hline $\begin{array}{l}\text { Myiothlypis leucoblephara } \\
\text { (Vieillot, 1817) }\end{array}$ & $\begin{array}{l}\text { pula-pula- } \\
\text { assobiador }\end{array}$ & G \\
\hline \multicolumn{3}{|l|}{ Icteridae Vigors, 1825} \\
\hline $\begin{array}{l}\text { Cacicus chrysopterus (Vigors, } \\
1825 \text { ) }\end{array}$ & tecelão & $\mathrm{E}$ \\
\hline $\begin{array}{l}\text { Cacicus haemorrhous (Linnaeus, } \\
1766 \text { ) }\end{array}$ & guaxe & G \\
\hline $\begin{array}{l}\text { Icterus cayanensis (Linnaeus, } \\
1766 \text { ) }\end{array}$ & inhapim & G \\
\hline $\begin{array}{l}\text { Pseudoleistes guirahuro (Vieillot, } \\
\text { 1819) }\end{array}$ & chopim-do-brejo & $\mathrm{C}$ \\
\hline $\begin{array}{l}\text { Molothrus bonariensis (Gmelin, } \\
\text { 1789) }\end{array}$ & vira-bosta & $\mathrm{C}$ \\
\hline $\begin{array}{l}\text { Sturnella superciliaris (Bonaparte, } \\
1850 \text { ) }\end{array}$ & $\begin{array}{l}\text { polícia-inglesa- } \\
\text { do-sul }\end{array}$ & $\mathrm{C}$ \\
\hline \multicolumn{3}{|l|}{ Thraupidae Cabanis, 1847} \\
\hline Coereba flaveola (Linnaeus, 1758) & cambacica & G \\
\hline $\begin{array}{l}\text { Saltator similis d'Orbigny \& } \\
\text { Lafresnaye, } 1837\end{array}$ & $\begin{array}{l}\text { trinca-ferro- } \\
\text { verdadeiro }\end{array}$ & $\mathrm{G}$ \\
\hline $\begin{array}{l}\text { Pyrrhocoma ruficeps (Strickland, } \\
\text { 1844) }\end{array}$ & $\begin{array}{l}\text { cabecinha- } \\
\text { castanha }\end{array}$ & $\mathrm{E}$ \\
\hline $\begin{array}{l}\text { Tachyphonus coronatus (Vieillot, } \\
\text { 1822) }\end{array}$ & tiê-preto & G \\
\hline Tangara sayaca (Linnaeus, 1766) & sanhaçu-cinzento & G \\
\hline Tangara preciosa (Cabanis, 1850) & saíra-preciosa & G \\
\hline $\begin{array}{l}\text { Stephanophorus diadematus } \\
\text { (Temminck, 1823) }\end{array}$ & sanhaçu-frade & G \\
\hline $\begin{array}{l}\text { Pipraeidea melanonota (Vieillot, } \\
1819 \text { ) }\end{array}$ & saíra-viúva & G \\
\hline Tersina viridis (Illiger, 1811) & saí-andorinha & G \\
\hline $\begin{array}{l}\text { Hemithraupis guira (Linnaeus, } \\
1766 \text { ) }\end{array}$ & $\begin{array}{l}\text { saíra-de-papo- } \\
\text { preto }\end{array}$ & G \\
\hline $\begin{array}{l}\text { Conirostrum speciosum } \\
\text { (Temminck, 1824) }\end{array}$ & $\begin{array}{l}\text { figuinha-de-rabo- } \\
\text { castanho }\end{array}$ & G \\
\hline Haplospiza unicolor Cabanis, 1851 & cigarra-bambu & G \\
\hline $\begin{array}{l}\text { Poospiza lateralis (Nordmann, } \\
1835 \text { ) }\end{array}$ & quete & G \\
\hline Sicalis flaveola (Linnaeus, 1766) & $\begin{array}{l}\text { canário-da-terra- } \\
\text { verdadeiro }\end{array}$ & $\mathrm{C}$ \\
\hline Volatinia jacarina (Linnaeus, 1766) & tiziu & $\mathrm{C}$ \\
\hline \multicolumn{3}{|l|}{ Fringillidae Leach, 1820} \\
\hline $\begin{array}{l}\text { Sporagra magellanica (Vieillot, } \\
\text { 1805) }\end{array}$ & pintassilgo & G \\
\hline
\end{tabular}

Dois trabalhos utilizando o mesmo método em ambientes semelhantes aos amostrados no atual trabalho podem ser aqui comentados, pois são áreas pertencentes à mesma microrregião. No Colégio Florestal "Presidente Costa e Silva", no Município de Irati, Marcelino \& Adenesky-Filho (2008) amostraram uma área de 0,33 ha e registraram 41 espécies de aves distribuídas em 20 famílias. No Campus de Irati da Universidade Estadual do Centro-Oeste (UNICENTRO), foram registradas 58 espécies de aves, distribuídas em 28 famílias (Marcelino \& Silva, 2008), quando amostrada uma área de 22,4 ha.

Em relatório da Fundação de Pesquisas Florestais do Paraná (1990) foram registradas, através de observação, 114 espécies de aves na Floresta Nacional de Irati em diversos ambientes visitados. Volpato (2009) e Volpato et al. (2010) também registraram no local 114 espécies de aves, 19 anos depois, em um levantamento com maior esforço amostral; foi feita amostragem em floresta nativa, floresta de araucária plantada em regeneração e plantio homogêneo de pinheiro (Pinus sp.) com regeneração de sub-bosque; destas, 48 foram classificadas como espécies florestais-dependentes e 66 como espécies florestais-generalistas. No atual trabalho (Tabelas 2 e 3 ) foram registradas: 25 espécies especialistas florestais, o equivalente às espécies florestais-dependentes de Volpato (2009) e Volpato et al. (2010); e 72 espécies generalistas, o equivalente às espécies florestais-generalistas dos referidos autores; além de outras 27 espécies especialistas campestres ou aquáticas, a grande maioria registrada apenas fora dos fragmentos florestais.

Marcelino \& Romaniuk (2010), entre março de 2007 e junho de 2010, realizaram observações ocasionais na Floresta Nacional de Irati, percorrendo todos os ambientes e registrando 81 espécies de aves. Romaniuk et al. (2011) realizaram levantamento complementar de aves na Floresta Nacional de Irati, por meio de redeneblina (176 horas-rede), e registraram 19 espécies, distribuídas em 11 famílias. Em outro levantamento com 376 horas-rede, Romaniuk (2011) registrou 22 espécies em 14 famílias. Winagraski et al. (2011), durante 104 horas-rede, registraram 18 espécies distribuídas em 11 famílias na Estação Ecológica de Fernandes Pinheiro. 
Quanto ao status de conservação das espécies para o Estado do Paraná (Mikich \& Bérnils, 2004), quatro registros se destacam: 1) um indivíduo de Polioptila lactea no fragmento 5, espécie associada a interior e borda florestal, que consta na categoria EN - em perigo; 2) Mesembrinibis cayennensis nos fragmentos 3 e 6, espécie associada a áreas úmidas, classificada na categoria NT - quase ameaçada; 3) Accipiter superciliosus, de interior e borda florestal, que foi observada no fragmento 4; e 4) Leptasthenura striolata, de interior florestal, foi observada nos fragmentos $1 \mathrm{e}$ 2. Accipiter superciliosus e Leptasthenura striolata constam na categoria DD - dados insuficientes.

\section{Análise quantitativa}

Na Figura 1 podem ser observadas as estimativas de riqueza de espécies de aves realizadas através do estimador Bootstrap. As curvas de rarefação observadas não estabilizaram totalmente ao final das amostragens, ao passo que as curvas estimadas tiveram desempenho diferente em cada fragmento. É possível observar o início de estabilização no fragmento 1 após 65 indivíduos registrados; no fragmento 2 após 122 indivíduos amostrados; no 3 após 135 indivíduos registrados; no 4 após 105 indivíduos; no 5 não foram esboçadas assíntotas; e no 6 após 140 indivíduos, no qual o início da estabilização foi mais evidente.

A Frequência Relativa (FR) calculada para cada espécie em cada fragmento é apresentada na Tabela 4. As espécies consideradas mais frequentes foram aquelas com $\mathrm{FR}>1$.

No fragmento 1, as mais frequentes foram Pitangus sulphuratus e Zonotrichia capensis; no fragmento 2, Patagioenas picazuro, Pyrrhura frontalis, Sittasomus griseicapillus, Leptasthenura setaria, Chiroxiphia caudata, Cyanocorax chrysops, Basileuterus culicivorus e Myiothlypis leucoblephara; no fragmento 3, Patagioenas picazuro, Pyrrhura frontalis, Sittasomus griseicapillus, Pitangus sulphuratus, Cyanocorax chrysops, Zonotrichia capensis, Basileuterus culicivorus e Myiothlypis leucoblephara; no fragmento 4, Patagioenas picazuro, Sittasomus griseicapillus, Pitangus sulphuratus, Cyanocorax chrysops, Conirostrum speciosum e Zonotrichia capensis; no fragmento 5, Coragyps atratus, Pyrrhura frontalis, Pionus maximiliani, Trogon surrucura, Sittasomus griseicapillus, Pitangus sulphuratus, Cyanocorax chrysops, Turdus leucomelas, Turdus amaurochalinus, Tangara sayaca, Tersina viridis, Zonotrichia capensis, Basileuterus culicivorus e Myiothlypis leucoblephara; $\mathrm{e}$ no fragmento 6, as mais frequentes foram: Patagioenas picazuro, Leptotila verreauxi, Myiodynastes maculatus, Tyrannus melancholicus, Cyanocorax chrysops, Saltator similis, Tangara sayaca, Zonotrichia capensis, e Myiothlypis leucoblephara.

O resultado da análise de agrupamento hierárquico (cluster) para a toda a comunidade de aves registrada nos fragmentos 1 a 6 está apresentado na Figura 2 e para a comunidade de aves especialistas florestais registradas nos fragmentos 1 a 6, na Figura 3.

A Tabela 5 traz o índice de Valor de Cobertura calculado para cada espécie arbórea registrada nos fragmentos estudados, incluindo os indivíduos não identificados. Foram registradas 92 espécies de árvores (Figueiredo Filho et al., 2013). Esses dados foram os usados como matriz para a análise de agrupamento hierárquico (cluster) da vegetação (Figura 4). Os coeficientes de correlação cofenética foram 0,91 (dendrograma 1$), 0,96$ (dendrograma 2) e 0,95 (dendrograma 3 ).

Tabela 3. Número de espécies registradas por fragmento, durante os trajetos-irregulares, de acordo com a classificação por preferência de hábitat. Localidade Assungui, Fernandes Pinheiro, PR.

\begin{tabular}{cccccc}
\hline Fragmento & $\begin{array}{c}\text { Número de espécies especialistas } \\
\text { campestres ou aquáticas }\end{array}$ & $\begin{array}{c}\text { Número de espécies } \\
\text { generalistas }\end{array}$ & $\begin{array}{c}\text { Número de espécies } \\
\text { especialistas florestais }\end{array}$ & $\begin{array}{c}\text { Total de } \\
\text { espécies }\end{array}$ & $\begin{array}{c}\text { Total de indivíduos } \\
\text { registrados }\end{array}$ \\
\hline 1 & 2 & 28 & 7 & 37 & 98 \\
2 & 2 & 33 & 10 & 45 & 153 \\
3 & 1 & 42 & 2 & 36 & 37 \\
4 & 2 & 33 & 14 & 55 & 202 \\
5 & 1 & 40 & 5 & 49 & 262 \\
6 & 4 & 40 & 24 & & 102 \\
\hline
\end{tabular}




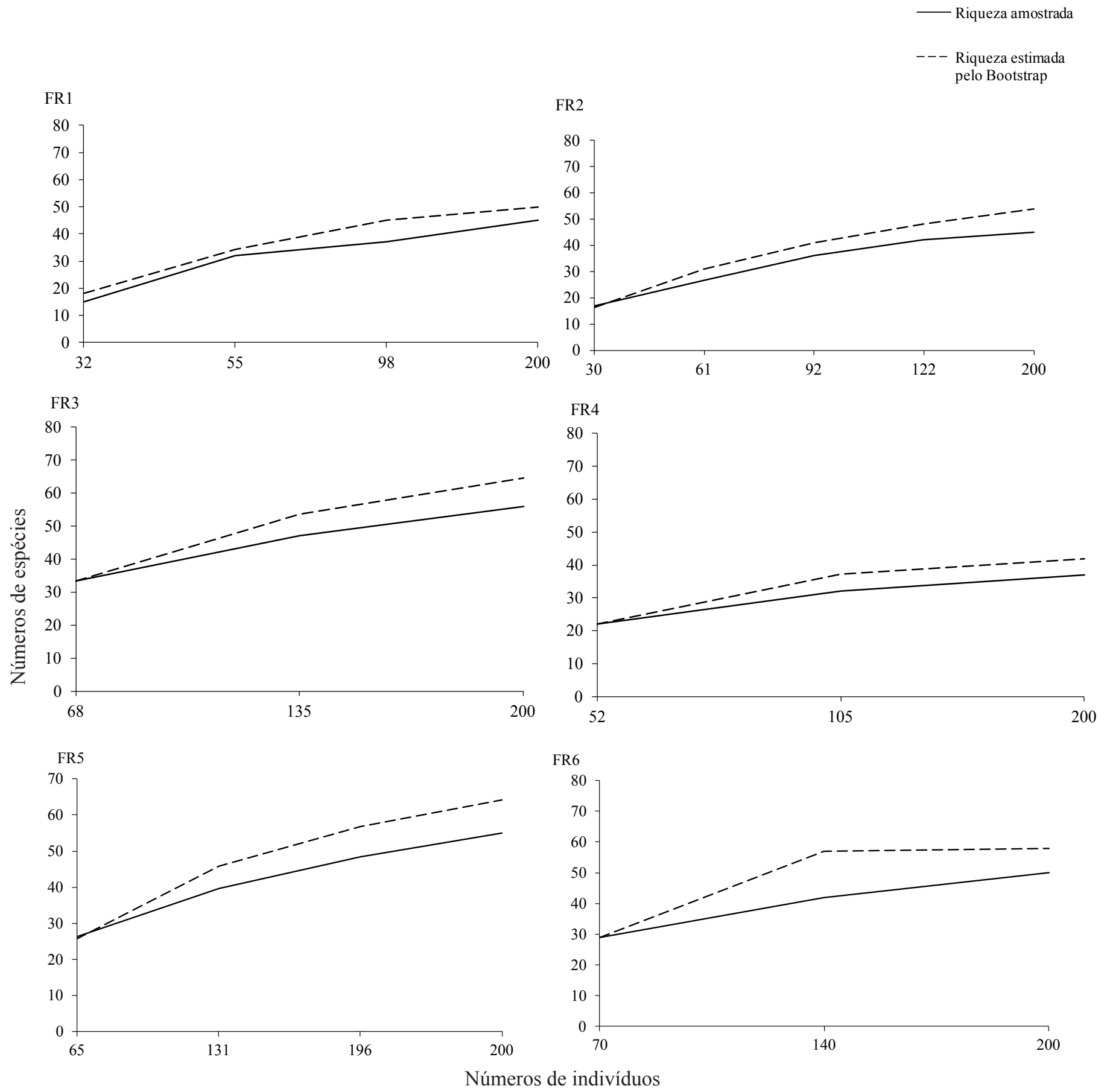

Figura 1. Estimativas de riqueza de espécies de aves para seis fragmentos na localidade Assungui, Fernandes Pinheiro, PR. As linhas representam o estimador Bootstrap e as espécies registradas em relação ao número de indivíduos. 


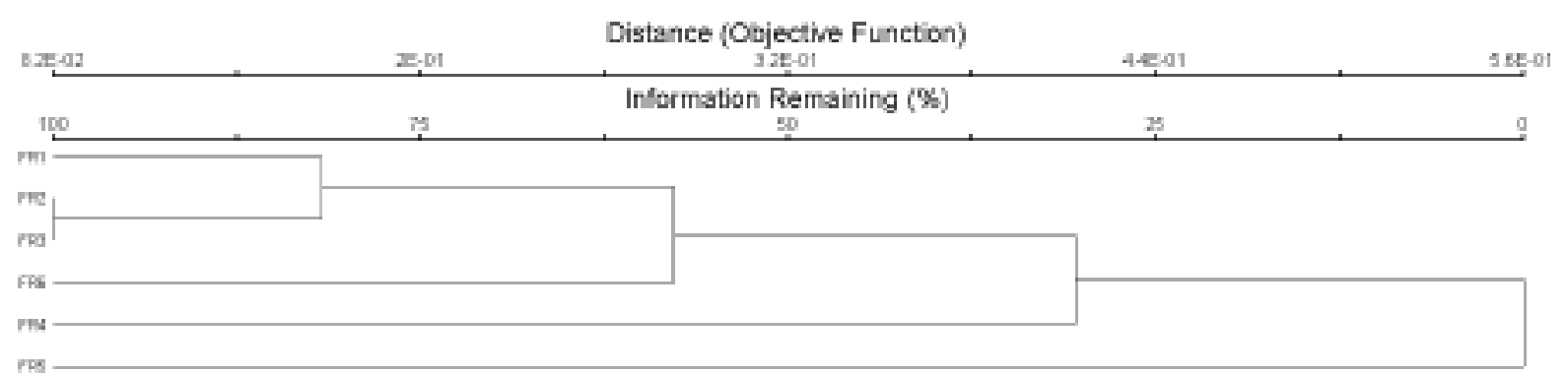

Figura 2. Análise de agrupamento hierárquico utilizando matriz de Frequência Relativa da comunidade de aves dos fragmentos amostrados em Fernandes Pinheiro, PR.

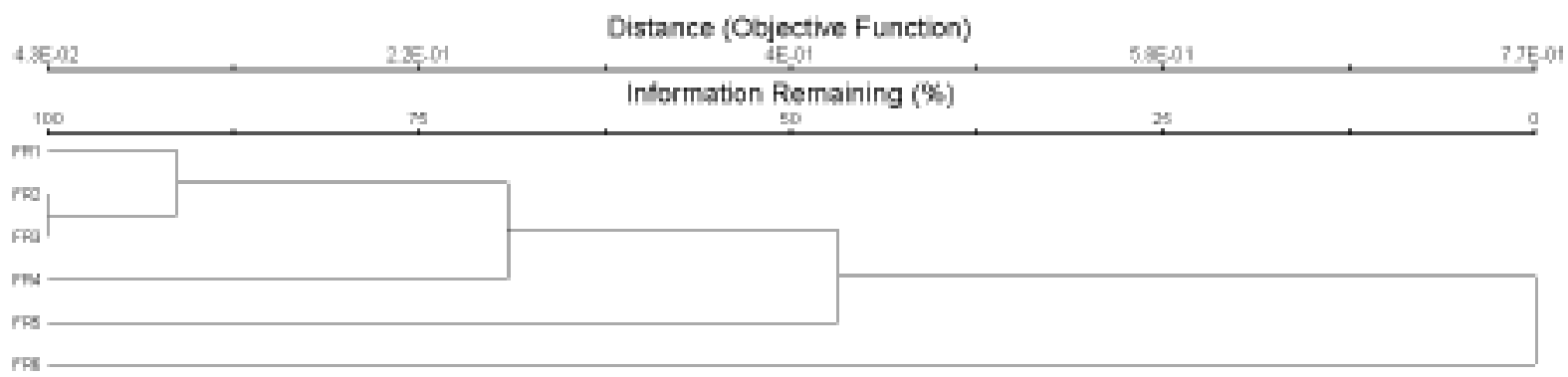

Figura 3. Análise de agrupamento hierárquico utilizando matriz de Frequência Relativa da comunidade de aves especialistas florestais dos fragmentos amostrados em Fernandes Pinheiro, PR.

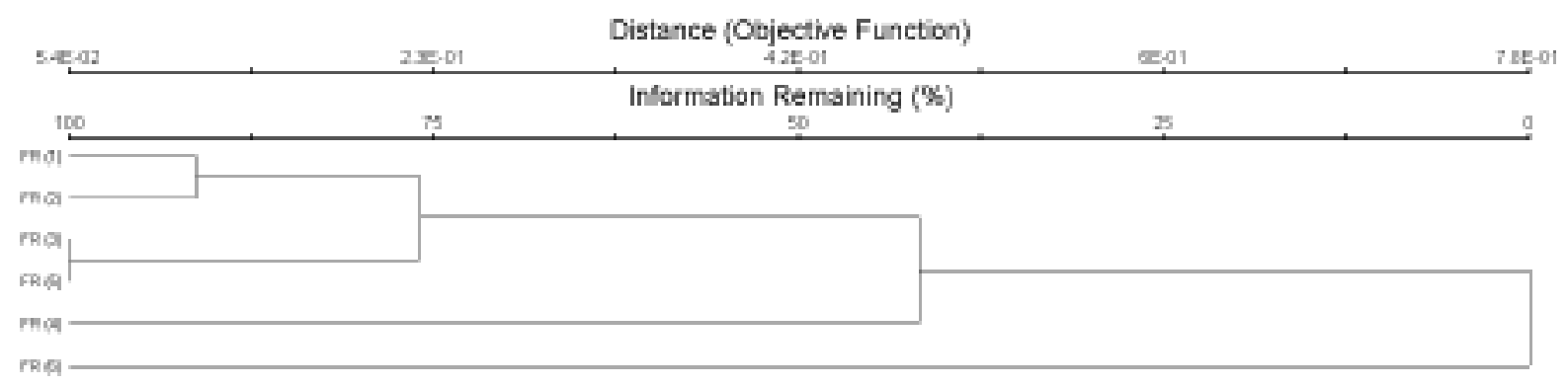

Figura 4. Análise de agrupamento hierárquico utilizando matriz de Valor de Cobertura da comunidade arbórea dos fragmentos amostrados em Fernandes Pinheiro, PR. 
Tabela 4. Frequência Relativa (FR) das espécies de aves registradas durante os trajetos-irregulares nos fragmentos florestais 1 a 6 estudados na localidade Assungui, Fernandes Pinheiro, PR.

\begin{tabular}{|c|c|c|c|c|c|c|}
\hline Espécie & $\begin{array}{l}\text { FR } \\
\text { (1) }\end{array}$ & $\begin{array}{l}\text { FR } \\
\text { (2) }\end{array}$ & $\begin{array}{l}\text { FR } \\
\text { (3) }\end{array}$ & $\begin{array}{l}\text { FR } \\
\text { (4) }\end{array}$ & $\begin{array}{l}\text { FR } \\
\text { (5) }\end{array}$ & $\begin{array}{l}\text { FR } \\
\text { (6) }\end{array}$ \\
\hline Crypturellus obsoletus & 0,00 & 0,33 & 0,17 & 0,00 & 0,00 & 0,33 \\
\hline Crypturellus tataupa & 0,00 & 0,33 & 0,00 & 0,00 & 0,00 & 0,17 \\
\hline Penelope obscura & 0,00 & 0,33 & 0,00 & 0,00 & 0,00 & 0,33 \\
\hline $\begin{array}{l}\text { Mesembrinibis } \\
\text { cayennensis }\end{array}$ & 0,00 & 0,00 & 0,33 & 0,00 & 0,00 & 0,17 \\
\hline Theristicus caudatus & 0,00 & 0,17 & 0,00 & 0,00 & 0,00 & 0,00 \\
\hline Coragyps atratus & 0,00 & 0,00 & 0,33 & 0,17 & 1,17 & 0,00 \\
\hline Accipiter superciliosus & 0,00 & 0,00 & 0,00 & 0,50 & 0,00 & 0,00 \\
\hline Rupornis magnirostris & 0,17 & 0,00 & 0,00 & 0,50 & 0,00 & 0,00 \\
\hline Aramides saracura & 0,00 & 0,33 & 0,50 & 0,00 & 0,00 & 0,67 \\
\hline Columbina talpacoti & 0,17 & 0,00 & 0,00 & 0,00 & 0,00 & 0,17 \\
\hline Patagioenas picazuro & 1,00 & 1,33 & 2,50 & 1,67 & 0,83 & 1,83 \\
\hline Zenaida auriculata & 0,00 & 0,00 & 0,00 & 0,00 & 0,00 & 0,17 \\
\hline Leptotila verreauxi & 0,33 & 0,50 & 0,67 & 0,67 & 0,00 & 1,50 \\
\hline Leptotila rufaxilla & 0,00 & 0,17 & 0,33 & 0,33 & 0,17 & 0,67 \\
\hline Trogon surrucura & 0,17 & 0,33 & 0,33 & 0,83 & 1,17 & 0,33 \\
\hline Ramphastos dicolorus & 0,00 & 0,00 & 0,33 & 0,00 & 0,83 & 0,00 \\
\hline Picumnus temminckii & 0,17 & 0,50 & 0,50 & 0,00 & 0,50 & 0,83 \\
\hline Melanerpes candidus & 0,17 & 0,50 & 0,00 & 0,33 & 0,50 & 0,00 \\
\hline Veniliornis spilogaster & 0,17 & 0,00 & 0,17 & 0,00 & 0,17 & 0,00 \\
\hline Piculus aurulentus & 0,00 & 0,00 & 0,00 & 0,00 & 0,33 & 0,00 \\
\hline Colaptes melanochloros & 0,00 & 0,00 & 0,00 & 0,17 & 0,00 & 0,00 \\
\hline Colaptes campestris & 0,00 & 0,17 & 0,00 & 0,00 & 0,17 & 0,00 \\
\hline Dryocopus lineatus & 0,00 & 0,00 & 0,33 & 0,00 & 0,17 & 0,00 \\
\hline Campephilus robustus & 0,33 & 0,00 & 0,33 & 0,00 & 0,00 & 0,00 \\
\hline Caracara plancus & 0,00 & 0,17 & 0,00 & 0,00 & 0,00 & 0,00 \\
\hline Milvago chimachima & 0,17 & 0,17 & 0,33 & 0,50 & 0,33 & 0,00 \\
\hline Herpetotheres cachinnans & 0,00 & 0,00 & 0,17 & 0,00 & 0,00 & 0,00 \\
\hline Pyrrhura frontalis & 1,00 & 1,33 & 1,83 & 0,00 & 3,00 & 0,00 \\
\hline Pionus maximiliani & 0,00 & 0,17 & 0,33 & 0,83 & 4,33 & 0,00 \\
\hline Dysithamnus mentalis & 0,33 & 0,50 & 0,33 & 0,00 & 0,83 & 0,00 \\
\hline $\begin{array}{l}\text { Thamnophilus } \\
\text { caerulescens }\end{array}$ & 0,00 & 0,00 & 0,50 & 0,00 & 0,00 & 0,00 \\
\hline Hypoedaleus guttatus & 0,00 & 0,00 & 0,17 & 0,00 & 0,00 & 0,00 \\
\hline Drymophila malura & 0,00 & 0,00 & 0,00 & 0,00 & 0,00 & 0,67 \\
\hline
\end{tabular}

Tabela 4. Continuação.

\begin{tabular}{|c|c|c|c|c|c|c|}
\hline Espécie & $\begin{array}{l}\text { FR } \\
\text { (1) }\end{array}$ & $\begin{array}{l}\text { FR } \\
\text { (2) }\end{array}$ & $\begin{array}{l}\text { FR } \\
\text { (3) }\end{array}$ & $\begin{array}{l}\text { FR } \\
\text { (4) }\end{array}$ & $\begin{array}{l}\text { FR } \\
\text { (5) }\end{array}$ & $\begin{array}{l}\text { FR } \\
\text { (6) }\end{array}$ \\
\hline Conopopha & & 0,00 & 0,33 & 0,00 & 0,00 & 0,33 \\
\hline Chamaeza campanisona & 0,00 & 0,17 & 0,00 & 0,00 & 0,00 & 0,00 \\
\hline Sclerurus scansor & 0,00 & 0,33 & 0,00 & 0,00 & 0,00 & 0,00 \\
\hline Sittasomus griseicapillus & 1,00 & 1,83 & 1,17 & 1,17 & 1,50 & 0,33 \\
\hline Lepidocolaptes squamatus & 0,00 & 0,00 & 0,17 & 0,00 & 0,17 & 0,00 \\
\hline Lepidocolaptes falcinellus & 0,17 & 0,33 & 1,00 & 0,00 & 0,17 & 0,00 \\
\hline $\begin{array}{l}\text { Dendrocolaptes } \\
\text { platyrostris }\end{array}$ & 0,00 & 0,17 & 0,33 & 0,50 & 0,00 & 0,17 \\
\hline Xiphocolaptes albic & 0,00 & 0,00 & 0,00 & 0,00 & 0,33 & 0,00 \\
\hline Furnarius rufus & 0,33 & 0,00 & 0,00 & 0,67 & 0,00 & 0,50 \\
\hline Lochmias nematura & 0,00 & 0,00 & 0,00 & 0,00 & 0,00 & 0,33 \\
\hline Philydor rufum & 0,00 & 0,00 & 0,33 & 0,00 & 0,17 & 0,33 \\
\hline Heliobletus contam & 0,17 & 0,00 & 0,00 & 0,00 & 0,00 & 0,00 \\
\hline Leptasthenura striolata & 0,17 & 0,50 & 0,00 & 0,00 & 0,00 & 0,00 \\
\hline Leptasthenura setaria & 0,17 & 1,67 & 0,00 & 0,83 & 0,33 & 0,00 \\
\hline Synallaxis cineras & 0,00 & 0,00 & 0,67 & 0,00 & 0,50 & 0,33 \\
\hline Synallaxis & 0,00 & 0,00 & 0,17 & 0,00 & 0,67 & 0,50 \\
\hline Chiroxiphia caudata & 0,00 & 1,33 & 0,00 & 0,00 & 0,00 & 0,00 \\
\hline Tityra inquisitor & 0,00 & 0,00 & 0,00 & 0,00 & 0,33 & 0,00 \\
\hline Pachyramphus ca. & 0,17 & 0,00 & 0,00 & 0,00 & 0,33 & 0,00 \\
\hline Pachyramphus validus & 0,00 & 0,00 & 0,00 & 0,00 & 0,00 & 0,67 \\
\hline Platyrinchus mystaceus & 0,00 & 0,50 & 0,00 & 0,00 & 0,00 & 0,00 \\
\hline Mionectes rufiventris & 0,00 & 0,00 & 0,17 & 0,00 & 0,00 & 0,00 \\
\hline Phylloscar & 0,00 & 0,00 & 0,33 & 0,33 & 0,00 & 0,00 \\
\hline Tolmomyias sulphure & 0,00 & 0,33 & 0,50 & 0,00 & 0,17 & 0,50 \\
\hline $\begin{array}{l}\text { Poecilotric } \\
\text { plumbeicep }\end{array}$ & 0,17 & 0,50 & 1,00 & 0,00 & 0,17 & 0,33 \\
\hline Camptostoma obsoletum & 0,67 & 0,33 & 0,17 & 1,00 & 0,83 & 0,67 \\
\hline Elaenic & 0,00 & 0,00 & 0,00 & 0,00 & 0,00 & 0,83 \\
\hline Elaenia parvirostris & 0,00 & 0,00 & 0,00 & 0,00 & 0,00 & 0,33 \\
\hline Capsiempis flaveola & 0,00 & 0,00 & 0,33 & 0,00 & 0,00 & 0,00 \\
\hline Phyllomyias virescens & 0,00 & 0,00 & 0,00 & 0,17 & 0,00 & 0,00 \\
\hline Phyllomyias fasciatus & 0,50 & 0,00 & 0,17 & 0,00 & 0,33 & 0,00 \\
\hline Pitangus sulphuratus & 1,50 & 0,33 & 1,33 & 2,00 & 1,67 & 0,83 \\
\hline Myiodynastes maculatus & 0,67 & 0,33 & 0,00 & 0,67 & 0,33 & 1,67 \\
\hline Megarynch & 0,17 & 0,17 & 0,17 & 0,17 & 0,83 & 0,17 \\
\hline Tyrannus melancholicus & 0,33 & 0,00 & 0,00 & 0,00 & 0,33 & 1,33 \\
\hline
\end{tabular}

Pesq. flor. bras., Colombo, v. 34, n. 77, p. 73-89, jan./mar. 2014 
Tabela 4. Continuação.

\begin{tabular}{|c|c|c|c|c|c|c|}
\hline Espécie & $\begin{array}{l}\text { FR } \\
\text { (1) }\end{array}$ & $\begin{array}{l}\text { FR } \\
\text { (2) }\end{array}$ & $\begin{array}{l}\text { FR } \\
\text { (3) }\end{array}$ & $\begin{array}{l}\text { FR } \\
\text { (4) }\end{array}$ & $\begin{array}{l}\text { FR } \\
\text { (5) }\end{array}$ & $\begin{array}{l}\text { FR } \\
(6)\end{array}$ \\
\hline Tyrannus savana & 0,00 & 0,00 & 0,00 & 0,00 & 0,00 & 0,17 \\
\hline Lathrotriccus euleri & 0,00 & 0,17 & 0,00 & 0,00 & 0,00 & 0,00 \\
\hline Cyclarhis gujanensis & 0,33 & 0,67 & 0,67 & 0,00 & 0,33 & 0,33 \\
\hline Vireo chivi & 0,00 & 0,00 & 0,00 & 0,17 & 0,00 & 0,17 \\
\hline Cyanocorax caeruleus & 0,00 & 0,00 & 0,17 & 0,00 & 0,00 & 0,00 \\
\hline Cyanocorax chrysops & 0,83 & 1,50 & 1,50 & 1,33 & 1,17 & 2,17 \\
\hline Troglodytes musculus & 0,00 & 0,33 & 0,83 & 1,00 & 0,67 & 0,50 \\
\hline Polioptila lactea & 0,00 & 0,00 & 0,00 & 0,00 & 0,17 & 0,00 \\
\hline Turdus leucomelas & 0,17 & 0,17 & 0,00 & 0,83 & 2,33 & 0,33 \\
\hline Turdus rufiventris & 0,83 & 0,33 & 0,83 & 0,50 & 0,33 & 1,00 \\
\hline Turdus amaurochalinus & 0,17 & 0,50 & 0,67 & 0,83 & 1,67 & 1,00 \\
\hline Turdus albicollis & 0,00 & 0,00 & 0,00 & 0,00 & 0,50 & 0,00 \\
\hline Zonotrichia capensis & 1,17 & 0,83 & 2,50 & 3,00 & 1,83 & 2,83 \\
\hline Setophaga pitiayumi & 0,50 & 0,33 & 0,33 & 0,33 & 0,17 & 1,00 \\
\hline Basileuterus culicivorus & 1,00 & 1,33 & 1,83 & 0,83 & 2,17 & 0,83 \\
\hline Myiothlypis leucoblephara & 0,67 & 1,50 & 2,50 & 0,00 & 1,50 & 1,67 \\
\hline Cacicus chrysopterus & 0,00 & 0,00 & 0,00 & 0,00 & 0,17 & 0,00 \\
\hline Cacicus haemorrhous & 0,00 & 0,00 & 0,00 & 0,33 & 0,00 & 1,00 \\
\hline Icterus cayanensis & 0,00 & 0,00 & 0,00 & 0,17 & 0,00 & 0,00 \\
\hline Sturnella superciliaris & 0,00 & 0,00 & 0,00 & 0,17 & 0,00 & 0,00 \\
\hline Coereba flaveola & 0,00 & 0,00 & 0,33 & 0,00 & 0,00 & 0,00 \\
\hline Saltator similis & 0,17 & 1,00 & 0,50 & 0,00 & 0,17 & 1,17 \\
\hline Pyrrhocoma ruficeps & 0,00 & 0,00 & 0,17 & 0,00 & 0,17 & 0,00 \\
\hline Tachyphonus coronatus & 0,00 & 0,00 & 0,00 & 0,00 & 0,67 & 0,00 \\
\hline Tangara sayaca & 0,00 & 0,00 & 0,00 & 0,33 & 1,50 & 1,33 \\
\hline Tangara preciosa & 0,17 & 0,00 & 0,00 & 0,00 & 0,50 & 0,00 \\
\hline $\begin{array}{l}\text { Stephanophorus } \\
\text { diadematus }\end{array}$ & 0,00 & 0,00 & 0,17 & 0,00 & 0,67 & 0,00 \\
\hline Pipraeidea melanonota & 0,00 & 0,00 & 0,00 & 0,33 & 0,83 & 0,17 \\
\hline Tersina viridis & 0,00 & 0,00 & 0,00 & 0,00 & 1,83 & 0,00 \\
\hline Hemithraupis guira & 0,00 & 0,00 & 0,33 & 0,00 & 0,00 & 0,00 \\
\hline Conirostrum speciosum & 0,00 & 0,00 & 0,67 & 1,83 & 0,67 & 0,33 \\
\hline Haplospiza unicolor & 0,00 & 0,00 & 0,33 & 0,00 & 0,00 & 0,00 \\
\hline Poospiza lateralis & 0,00 & 0,00 & 0,17 & 0,00 & 0,00 & 0,33 \\
\hline Sporagra magellanica & 0,00 & 0,67 & 0,33 & 0,33 & 0,00 & 0,00 \\
\hline
\end{tabular}

As análises de agrupamento mostraram poucos grupos de fragmentos próximos, demonstrando que os fragmentos são bastante heterogêneos com relação às comunidades arbóreas e de aves. Na análise da comunidade geral de aves, os fragmentos 2 e 3 se mostram mais próximos, o mesmo acontecendo com a comunidade arbórea. Quando analisada apenas a matriz da avifauna especialista florestal, os fragmentos 3 e 5 estão bem mais próximos.

O teste de Mantel apontou correlação significativa entre a matriz de Valor de Cobertura das espécies arbóreas e a matriz de Frequência Relativa da comunidade de aves em geral $(r=0,48 ; p=0,10)$. Apontou ainda uma correlação significativa mais estreita da vegetação dos remanescentes florestais com as aves especialistas florestais $(\mathrm{r}=0,73$; $\mathrm{p}=0,04)$, demonstando a alta dependência desse grupo de aves com a qualidade da vegetação.

$\mathrm{O}$ fragmento 5 apresentou uma das maiores riquezas (55 espécies) e número de indivíduos registrados (262). Esses parâmetros são indicativos de que esse fragmento é próximo, em riqueza e abundância, do fragmento 3 (56 espécies e 202 indivíduos); e próximo também dos fragmentos 2 (45 espécies e 153 indivíduos) e 6 (49 espécies e 206 indivíduos).

Estando os fragmentos 2, 3 e 6 em estágio avançado de sucessão, pode-se especular que o uso da Floresta com Araucária como "potreiro" de equinos (fragmento 5) é menos impactante (negativamente) para a avifauna do que o uso para bovinos. Durante as visitas de reconhecimento, verificou-se que os "potreiros" com bovinos apresentam quase todo o estrato herbáceo substituído por gramíneas exóticas, enquanto que no remanescente com equinos há substituição parcial do estrato apenas em trilhas de cerca de $1 \mathrm{~m}$ de largura. Talvez o levantamento detalhado do histórico de uso de tais remanescentes pudesse esclarecer melhor esta questão.

Outra característica que pode estar influindo na maior diversidade encontrada no fragmento 5 talvez seja o fato de haver mais fragmentos bosqueados que lhe são contínuos, aumentando a área de hábitat disponível para essas espécies e fazendo ligação ou aproximando-o de fragmentos em estágio avançado de sucessão. Os fragmentos melhor conservados, em estágio avançado de sucessão e pouco alterados, devem estar servindo de fonte de espécies especialistas florestais que exploram os recursos alimentícios disponíveis nos fragmentos bosqueados presentes na matriz. 
Tabela 5. Valor de Cobertura (VC) das espécies arbóreas registradas nos fragmentos florestais (1 a 6) na localidade Assungui, Fernandes Pinheiro, PR.

\begin{tabular}{|c|c|c|c|c|c|c|c|}
\hline Família & Espécie & $\begin{array}{l}\mathrm{VC} \\
(1)\end{array}$ & $\begin{array}{l}\mathrm{VC} \\
(2)\end{array}$ & $\begin{array}{l}\mathrm{VC} \\
\text { (3) }\end{array}$ & $\begin{array}{l}\mathrm{VC} \\
(4) \\
\end{array}$ & $\begin{array}{l}\mathrm{VC} \\
\text { (5) }\end{array}$ & $\begin{array}{l}\mathrm{VC} \\
(6)\end{array}$ \\
\hline \multirow{3}{*}{ Anacardiaceae } & Lithraea brasiliensis Marchand & 2,4 & 0,7 & 0,1 & 0,0 & 0,2 & 0,0 \\
\hline & Lithraea molleoides (Vell.) Engl. & 3,5 & 2,6 & 2,8 & 0,0 & 0,3 & 0,0 \\
\hline & Schinus terebinthifolius Raddi & 0,0 & 0,0 & 0,0 & 0,3 & 0,0 & 0,0 \\
\hline Annonaceae & Annona rugulosa (Schltdl.) H.Rainer & 0,0 & 0,1 & 0,0 & 0,2 & 0,0 & 0,0 \\
\hline \multirow[t]{3}{*}{ Aquifoliaceae } & Ilex dumosa Reissek & 1,1 & 0,2 & 1,3 & 0,3 & 0,0 & 0,0 \\
\hline & Ilex paraguariensis A. St.-Hil. & 0,7 & 0,8 & 0,0 & 1,4 & 1,3 & 0,0 \\
\hline & Ilex theezans Mart. ex Reissek & 0,9 & 1,0 & 1,3 & 0,4 & 0,0 & 2,9 \\
\hline Araliaceae & Schefflera morototoni (Aubl.) Maguire et al. & 0,0 & 0,0 & 0,0 & 0,0 & 0,2 & 0,0 \\
\hline Araucareaceae & Araucaria angustifolia (Bertol.) Kuntze & 27,4 & 22,0 & 29,6 & 21,9 & 16,2 & 0,0 \\
\hline Arecaceae & Syagrus romanzoffiana (Cham.) Glassman & 0,0 & 2,8 & 3,2 & 0,0 & 11,2 & 6,8 \\
\hline \multirow{4}{*}{ Asteraceae } & Gochnatia polymorpha (Less.) Cabrera & 1,3 & 0,5 & 0,4 & 0,0 & 0,0 & 0,0 \\
\hline & Piptocarpha angustifolia Dusén ex Malme & 0,0 & 0,0 & 0,0 & 0,0 & 1,3 & 0,0 \\
\hline & Piptocarpha axillaris (Less.) Baker & 0,3 & 0,7 & 0,4 & 0,0 & 9,9 & 3,3 \\
\hline & Raulinoreitzia leptophlebia (B.L.Rob.) R.M.King \& H.Rob. & 0,0 & 0,2 & 0,0 & 0,0 & 0,3 & 0,0 \\
\hline \multirow[t]{2}{*}{ Bignoniaceae } & Handroanthus albus (Cham.) Mattos & 0,2 & 0,0 & 0,6 & 0,0 & 0,0 & 0,0 \\
\hline & Jacaranda micrantha Cham. & 0,0 & 0,2 & 0,2 & 0,0 & 0,1 & 4,3 \\
\hline \multirow[t]{2}{*}{ Canellaceae } & Cinnamodendron dinisii Schwacke & 12,8 & 3,9 & 1,8 & 34,4 & 4,8 & 0,0 \\
\hline & Cinnamomum amoenum (Nees \& Mart.) Kosterm. & 2,0 & 6,4 & 9,7 & 0,5 & 0,3 & 0,0 \\
\hline Cannabaceae & Trema micrantha (L.) Blume & 0,0 & 0,0 & 0,0 & 0,0 & 0,1 & 0,0 \\
\hline Cardiopteredaceae & Citronella paniculata (Mart.) R.A.Howard & 0,0 & 0,3 & 0,3 & 0,0 & 0,1 & 0,0 \\
\hline Clethraceae & Clethra scabra Pers. & 4,6 & 10,2 & 10,6 & 0,0 & 0,4 & 20,0 \\
\hline Cunoniaceae & Lamanonia ternata Vell. & 0,1 & 0,2 & 0,2 & 0,0 & 0,0 & 0,0 \\
\hline Elaeocarpaceae & Sloanea hirsuta (Schott) Planch. ex Benth. & 0,0 & 0,1 & 0,0 & 0,0 & 0,5 & 0,0 \\
\hline \multirow[t]{2}{*}{ Erythroxylaceae } & Erythroxylum argentinum O.E.Schulz & 0,0 & 0,2 & 0,0 & 0,0 & 0,0 & 0,0 \\
\hline & Erythroxylum deciduum A. St.-Hil. & 1,1 & 0,3 & 0,5 & 0,6 & 0,0 & 0,0 \\
\hline \multirow[t]{3}{*}{ Euphorbiaceae } & Sapium glandulosum (L.) Morong & 0,1 & 0,2 & 0,0 & 0,2 & 0,0 & 0,0 \\
\hline & Sebastiania brasiliensis Spreng. & 0,0 & 0,0 & 0,0 & 0,0 & 0,1 & 0,0 \\
\hline & Sebastiania commersoniana (Baill.) L.B.Sm. \& Downs & 0,3 & 0,1 & 0,0 & 0,0 & 0,1 & 4,0 \\
\hline \multirow[t]{8}{*}{ Fabaceae } & Albizia edwallii (Hoehne) Barneby \& J.W.Grimes & 0,0 & 0,1 & 0,0 & 0,0 & 0,0 & 0,0 \\
\hline & Ateleia glazioveana Baill. & 0,0 & 0,0 & 0,0 & 0,0 & 0,3 & 1,0 \\
\hline & Cassia leptophylla Vogel & 0,0 & 0,0 & 0,0 & 1,0 & 0,2 & 0,0 \\
\hline & Dalbergia brasiliensis Vogel & 0,0 & 0,1 & 0,0 & 0,0 & 0,1 & 7,0 \\
\hline & Inga virescens Benth. & 0,0 & 0,0 & 0,0 & 0,0 & 0,1 & 1,1 \\
\hline & Machaerium stipitatum (DC.) Vogel & 0,0 & 0,1 & 0,0 & 0,0 & 0,0 & 2,2 \\
\hline & Mimosa scabrella Benth. & 0,0 & 0,0 & 0,0 & 0,0 & 1,3 & 1,2 \\
\hline & Parapiptadenia rigida (Benth.) Brenan & 0,1 & 0,0 & 0,0 & 0,0 & 0,1 & 0,0 \\
\hline
\end{tabular}

As espécies são apresentadas em ordem alfabética das famílias, seguida dos nomes científicos. 
Tabela 5. Continuação.

\begin{tabular}{|c|c|c|c|c|c|c|c|}
\hline Família & Espécie & $\begin{array}{l}\text { VC } \\
\text { (1) }\end{array}$ & $\begin{array}{l}\mathrm{VC} \\
(2)\end{array}$ & $\begin{array}{l}\text { VC } \\
\text { (3) }\end{array}$ & $\begin{array}{l}\text { VC } \\
\text { (4) }\end{array}$ & $\begin{array}{l}\text { VC } \\
\text { (5) }\end{array}$ & $\begin{array}{l}\text { VC } \\
\text { (6) }\end{array}$ \\
\hline \multirow[t]{2}{*}{ Lamiaceae } & Aegiphila integrifolia (Jacq.) Moldenke & 0,0 & 0,0 & 0,0 & 0,3 & 0,0 & 0,0 \\
\hline & Vitex megapotamica (Spreng.) Moldenke & 0,0 & 0,2 & 0,2 & 0,0 & 0,0 & 0,0 \\
\hline \multirow[t]{12}{*}{ Lauraceae } & Cryptocarya aschersoniana $\mathrm{Mez}$ & 0,0 & 0,0 & 0,2 & 0,4 & 0,0 & 0,0 \\
\hline & Nectandra grandiflora Nees & 14,9 & 10,1 & 15,8 & 1,3 & 2,4 & 0,0 \\
\hline & Nectandra lanceolata Nees & 0,0 & 0,3 & 0,1 & 0,9 & 1,2 & 0,0 \\
\hline & Nectandra megapotamica (Spreng.) Mez & 0,0 & 0,1 & 0,3 & 0,0 & 0,0 & 0,0 \\
\hline & Ocotea acutifolia (Ness) Mez & 0,0 & 0,0 & 0,1 & 0,0 & 0,0 & 0,0 \\
\hline & Ocotea corymbosa (Meisn.) Mez & 0,6 & 0,1 & 0,1 & 0,0 & 0,0 & 0,0 \\
\hline & Ocotea diospyrifolia (Meisn.) Mez & 0,0 & 0,1 & 0,6 & 0,0 & 2,6 & 0,0 \\
\hline & Ocotea odorifera (Vell.) Rohwer & 0,0 & 0,0 & 0,0 & 0,0 & 0,1 & 0,0 \\
\hline & Ocotea porosa (Nees \& Mart.) Barroso & 0,7 & 4,7 & 9,5 & 15,6 & 6,6 & 0,0 \\
\hline & Ocotea puberula (Rich.) Nees & 0,0 & 0,0 & 0,0 & 1,5 & 3,2 & 8,8 \\
\hline & Ocotea pulchella (Nees \& Mart.) Mez & 0,1 & 0,0 & 0,0 & 0,0 & 0,0 & 0,0 \\
\hline & Persea major (Meisn.) L.E.Kopp & 0,0 & 0,5 & 0,0 & 0,0 & 0,0 & 0,0 \\
\hline Meliaceae & Cedrela fissilis Vell. & 0,0 & 0,5 & 0,0 & 0,0 & 0,9 & 2,0 \\
\hline \multirow[t]{12}{*}{ Myrtaceae } & Blepharocalyx salicifolius (Kunth) O.Berg & 1,7 & 0,3 & 0,3 & 0,4 & 0,1 & 0,0 \\
\hline & Calyptranthes concinna DC. & 0,1 & 0,2 & 0,0 & 0,0 & 0,0 & 0,0 \\
\hline & Campomanesia guazumifolia (Cambess.) O.Berg & 0,0 & 0,0 & 0,0 & 0,0 & 0,3 & 0,0 \\
\hline & Campomanesia xanthocarpa (Mart.) O.Berg & 1,6 & 5,8 & 0,5 & 1,5 & 5,0 & 0,0 \\
\hline & Curitiba prismatica (D.Legrand) Salywon \& Landrum & 1,9 & 0,1 & 0,0 & 3,2 & 1,8 & 0,0 \\
\hline & Myrceugenia euosma (O.Berg) D.Legrand & 3,3 & 0,5 & 0,9 & 0,0 & 0,2 & 1,0 \\
\hline & Myrceugenia miersiana (Gardner) D. Legrand \& Kausel & 0,0 & 0,1 & 0,0 & 0,0 & 0,0 & 0,0 \\
\hline & Myrcia hebepetala DC. & 0,3 & 0,1 & 0,0 & 0,0 & 0,2 & 0,0 \\
\hline & Myrcia lajeana D. Legrand & 0,0 & 0,1 & 0,0 & 0,0 & 0,0 & 0,0 \\
\hline & Myrcia splendens (Sw.) DC. & 0,6 & 2,5 & 0,1 & 0,0 & 0,7 & 0,0 \\
\hline & Myrcianthes gigantea (D.Legrand) D.Legrand & 0,0 & 0,1 & 0,0 & 0,0 & 0,0 & 0,0 \\
\hline & Myrciaria delicatula (DC.) O.Berg & 0,0 & 0,1 & 0,0 & 0,0 & 0,0 & 0,0 \\
\hline Podocarpaceae & Podocarpus lambertii Klotzsch ex Endl. & 0,0 & 0,0 & 0,0 & 0,0 & 0,0 & 2,6 \\
\hline \multirow[t]{3}{*}{ Primulaceae } & Myrsine coriacea (Sw.) R.Br. ex Roem. \& Schult. & 0,1 & 0,1 & 0,0 & 0,0 & 0,6 & 2,2 \\
\hline & Myrsine guianensis (Aubl.) Kuntze & 0,0 & 0,2 & 0,2 & 0,0 & 0,0 & 0,0 \\
\hline & Myrsine umbellata Mart. & 0,0 & 0,0 & 0,0 & 0,0 & 1,6 & 0,0 \\
\hline Proteaceae & Roupala montana Aubl. & 0,0 & 0,2 & 1,1 & 0,0 & 0,0 & 0,0 \\
\hline Rhamnaceae & Hovenia dulcis Thunb. & 0,0 & 0,1 & 0,0 & 0,5 & 3,9 & 3,9 \\
\hline Rosaceae & Prunus myrtifolia (L.) Urb. & 0,6 & 0,7 & 0,0 & 0,0 & 0,8 & 1,9 \\
\hline \multirow[t]{3}{*}{ Rubiaceae } & Coussarea contracta (Walp.) Müll.Arg. & 0,0 & 0,0 & 0,0 & 0,0 & 1,1 & 0,0 \\
\hline & Psychotria vellosiana Benth. & 0,0 & 0,0 & 0,0 & 0,0 & 1,2 & 0,0 \\
\hline & Rudgea jasminoides (Cham.) Müll.Arg. & 0,0 & 0,1 & 0,1 & 0,0 & 0,4 & 0,0 \\
\hline
\end{tabular}

As espécies são apresentadas em ordem alfabética das famílias, seguida dos nomes científicos. 
Tabela 5. Continuação.

\begin{tabular}{|c|c|c|c|c|c|c|c|}
\hline Família & Espécie & $\begin{array}{l}\text { VC } \\
\text { (1) }\end{array}$ & $\begin{array}{l}\mathrm{VC} \\
\text { (2) }\end{array}$ & $\begin{array}{l}\text { VC } \\
\text { (3) }\end{array}$ & $\begin{array}{l}\text { VC } \\
\text { (4) }\end{array}$ & $\begin{array}{l}\mathrm{VC} \\
\text { (5) }\end{array}$ & $\begin{array}{l}\mathrm{VC} \\
\text { (6) }\end{array}$ \\
\hline \multirow[t]{2}{*}{ Rutaceae } & Zanthoxylum kleinii (R.S.Cowan) P.G. Waterman & 2,0 & 0,8 & 0,2 & 0,0 & 0,0 & 0,0 \\
\hline & Zanthoxylum rhoifolium Lam. & 0,2 & 0,1 & 0,1 & 0,6 & 0,1 & 6,5 \\
\hline \multirow[t]{6}{*}{ Salicaceae } & Casearia decandra Jacq. & 3,4 & 1,7 & 0,5 & 3,6 & 1,8 & 0,0 \\
\hline & Casearia gossypiosperma Briq. & 0,4 & 0,6 & 0,8 & 0,0 & 0,0 & 1,0 \\
\hline & Casearia lasiophylla Eichler & 0,0 & 0,0 & 0,0 & 0,2 & 0,3 & 0,0 \\
\hline & Casearia obliqua Spreng. & 1,7 & 3,6 & 0,0 & 7,2 & 3,8 & 2,5 \\
\hline & Casearia sylvestris Sw. & 0,0 & 0,4 & 0,0 & 0,0 & 0,3 & 6,2 \\
\hline & Xylosma pseudosalzmanii Sleumer & 0,0 & 0,0 & 0,0 & 0,0 & 0,2 & 0,0 \\
\hline \multirow[t]{4}{*}{ Sapindaceae } & Allophylus edulis (A.St.-Hil. et al.) Hieron. ex Niederl. & 0,4 & 0,1 & 0,0 & 0,6 & 0,2 & 1,2 \\
\hline & Allophylus petiolulatus Radlk. & 0,0 & 0,0 & 0,0 & 0,3 & 0,0 & 2,1 \\
\hline & Cupania vernalis Cambess. & 0,0 & 0,3 & 0,0 & 0,0 & 0,2 & 0,0 \\
\hline & Matayba elaeagnoides Radlk. & 5,0 & 9,4 & 2,4 & 0,0 & 5,7 & 2,5 \\
\hline Simaroubaceae & Picrasma crenata ( Vell.) Engl. & 0,1 & 0,0 & 0,0 & 0,2 & 0,2 & 0,0 \\
\hline Solanaceae & Solanum granulosoleprosum Dunal & 0,0 & 0,0 & 0,0 & 0,0 & 0,8 & 0,0 \\
\hline Styracaceae & Styrax leprosus Hook. \& Arn. & 0,0 & 0,0 & 0,4 & 0,0 & 0,0 & 1,0 \\
\hline Symplocaceae & Symplocos tenuifolia Brand. & 0,0 & 0,0 & 0,0 & 0,0 & 0,0 & 0,9 \\
\hline Theaceae & Laplacea fruticosa (Schrad.) Kobuski & 0,0 & 0,7 & 0,0 & 0,0 & 2,0 & 0,0 \\
\hline Winteraceae & Drimys brasiliensis Miers & 1,2 & 0,7 & 2,2 & 0,7 & 0,0 & 0,0 \\
\hline N.I. & N.I. & 0,1 & 0,2 & 0,1 & 0,0 & 0,0 & 0,0 \\
\hline
\end{tabular}

N.I. = indivíduo não identificado. As espécies são apresentadas em ordem alfabética das famílias, seguida dos nomes científicos.

\section{Conclusões}

Os fragmentos em geral estão beneficiando espécies de aves típicas de áreas mais abertas em detrimento das espécies mais exigentes em qualidade florestal (especialistas florestais). As matrizes de Frequência Relativa da comunidade de aves e seu subgrupo de especialistas florestais apresentaram correlação significativa com o Valor de Cobertura da comunidade arbórea. Assim, a vegetação explicou bem a presença e a frequência das espécies de aves.

A avifauna se mostrou um bom bioindicador do estado de conservação dos fragmentos, demonstrado pelas análises de agrupamento hierárquico que agruparam remanescentes semelhantes em biodiversidade; também demonstrado pela comparação com a vegetação arbórea, cuja estrutura e riqueza interferem diretamente na comunidade de aves.
É desejável que o monitoramento se torne ainda mais complexo, envolvendo uma amostragem mais completa das espécies de aves presentes na região. Para tanto, o uso do método de captura com redes-de-neblina é aconselhável em trabalhos posteriores.

De forma a aprofundar a discussão em torno da conservação de fauna e flora no mosaico de fragmentos da localidade Assungui, recomenda-se um estudo de ecologia de paisagem com foco na ligação entre os remanescentes.

\section{Agradecimentos}

Ao Carlos Henrique B. Nauiack, pelo gerenciamento do projeto. Às famílias dos proprietários. Ao técnico florestal e dendrólogo Gerson Luiz Lopes, pelo reconhecimento em campo das espécies arbóreas. 
Aos estagiários bolsistas do projeto que participaram do levantamento fitossociológico. À SETI pelo apoio financeiro. À Universidade de Rottenburg e ao estado de Baden-Württemberg, Alemanha, pela parceria estabelecida. À FAU pelo gerenciamento financeiro. À UNICENTRO pelo apoio logístico. Aos estagiários Roberto, Edenilson, Fernando e Leandro, pelo auxílio nos trabalhos de campo.

\section{Referências}

ANJOS, L.; SCHUCHMANN, K. L.; BERNDT, R. A. Avifaunal composition, species richness, and status in the Tibagi River Basin, Parana State, southern Brazil. Ornitologia Neotropical, Washington, DC, n. 8, p. 145-173, 1997.

BIBBY, C. J.; BURGUESS, N. D.; HILL, D. Bird census techniques. Londres: Academic Press, 1993. 257 p.

CAMPASSI, F. Padrões geográficos das síndromes de dispersão e características dos frutos de espécies arbustivo-arbóreas em comunidades vegetais da Mata Atlântica. 2006. 84 f. Dissertação (Mestrado em Ecologia de Agroecossistemas) - Universidade de São Paulo, Piracicaba.

CASTELLA, P. R.; BRITEZ, R. M. (Org.). A Floresta com Araucária no Paraná: conservação e diagnóstico dos remanescentes florestais. Brasília, DF: Ministério do Meio Ambiente, 2004. 236 p.

CAVIGLIONE, J. H.; KIIHL, L. R. B.; CARAMORI, P. H.; OLIVEIRA, D. Cartas climáticas do Paraná. Londrina: IAPAR, 2000. Disponível em: <http://www.iapar.br/modules/conteudo/ conteudo.php?conteudo=863>. Acesso em: 14 fev. 2014 .

COMITÊ BRASILEIRO DE REGISTROS ORNITOLÓGICOS. Listas das aves do Brasil. 11. ed. 2014. Disponível em: <http:// www.cbro.org.br>. Acesso em: 13 fev. 2014.

COLWELL, R. K. Estimates: statistical estimation of species richness and shared species from samples. Versão 8.2. User's Guide and Application. University of Connecticut, Storrs. 2009. Disponível em: <http://purl.oclc.org/estimates>. Acesso em 20 jan. 2014.

FIGUEIREDO FILHO, A.; NAUIACK, C. H. B.; ROIK, M.; GOMES, G. S. Inventário das florestas nativas em pequenas propriedades rurais na bacia do Imbituvão, Centro-Sul do Paraná. Irati, PR: UNICENTRO, 2013. Relatório técnico. Projeto estratégias para o manejo florestal sustentável em pequenas propriedades rurais no Centro-Sul do Paraná, Brasil.

FUNDAÇÃO DE PESQUISAS FLORESTAIS DO PARANÁ. Aspectos faunísticos da Floresta Nacional de Irati. Curitiba: IBAMA/FUPEF, 1990. Projeto manejo de florestas nacionais. Relatório Técnico.

GOTELLI, N. J.; COLWELL, R. K. Quatifying biodiversity: procedures and pitfalls in the measurement and comparison of species richness. Ecology Letters, v. 4, p. 379-391, 2001.

GOTELLI, N. J.; COLWELL, R. K. Estimating species richness. In: MAGURRAN, A. E.; McGILL, B. J. (Ed.). Frontiers in measuring biodiversity. New York: Oxford University Press, 2011.
HOWE, H. F.; SMALLWOOD, J. Ecology of seed dispersal. Annual review of ecology and systematics, Palo Alto, v. 13, p. 201-228, 1982.

LACERDA, A. E. B.; ROSOT, M. A. D.; FIGUEIREDO-FILHO, A.; GARRASTAZÚ, M. C.; NIMMO, E. R.; KELLERMANN, B.; RADOMSKI, M. I.; BEIMGRABEN, T.; MATTOS, P. P.; OLIVEIRA, Y. M. M. Sustainable forest management in rural southern Brazil: exploring participatory forest management planning. In: DIEZ, J. J. (Ed.). Sustainable forest management: case studies. [S.1.]: InTech, 2012. E-book. Disponível em: $<$ http://www. intechopen.com/books/sustainable-forest-management-currentresearch>. Acesso em: 19 mar. 2013.

LEGENDRE, P.; LEGENDRE, L. Numerical ecology. 2nd ed. Amsterdam, HO: Elsevier, 1998. 853 p.

McCUNE, B.; JAMES, B. G. Analysis of ecological communities. 1rd ed. Oregon, USA: MJM, 2002.

MARCELINO, V. R.; ADENESKI-FILHO, E. Aves e mamíferos registrados no Colégio Florestal de Irati, Paraná. In: SEMANA DE ESTUDOS FLORESTAIS, 10., 2008, Irati. Anais... Guarapuava: UNICENTRO, 2008.

MARCELINO, V. R.; ROMANIUK, D. S. Levantamento complementar das aves da Floresta Nacional de Irati, PR. In: SEMINÁRIO DE ATUALIZAÇÃO FLORESTAL, 2., 2010, Irati. Anais... Guarapuava: UNICENTRO, 2010.

MARCELINO, V. R.; SILVA, M. M. Aves e mamíferos registrados no Campus de Irati da UNICENTRO. In: SEMANA DE ESTUDOS FLORESTAIS, 10., 2008, Irati. 2008. Anais... Guarapuava: UNICENTRO, 2008.

MIKICH, S. B.; BÉRNILS, R. S. Livro vermelho da fauna ameaçada no Estado do Paraná. Curitiba: Instituto Ambiental do Paraná, 2004.

SICK, H. Ornitologia brasileira. Ed. Revista e ampliada por José Fernando Pacheco. 2. impressão. Rio de Janeiro, RJ: Nova Fronteira, 1997. 862 p.

ROMANIUK, D. S. Comparação da avifauna amostrada com rede-neblina em duas áreas florestais na FLONA de Irati, Paraná. 2011. Trabalho de Conclusão de Curso (Graduação em Engenharia Florestal) - Universidade Estadual do Centro-Oeste, Irati, PR.

ROMANIUK, D. S.; WINAGRASKI, E., MARCELINO V. R. Comparação qualitativa da avifauna de duas áreas com parcelas permanentes na Floresta Nacional de Irati usando redes-neblina como método amostral. In: SEMANA DE INTEGRAÇÃO ENSINO, PESQUISA E EXTENSÃO, 2., 2011, Irati, PR. Anais... Guarapuava: Universidade Estadual do Centro-Oeste, 2011.

VEloso, H. P.; RANGEL-FILHO, A. L. R.; LIMA, J. C. A. Classificação da vegetação brasileira, adaptada a um sistema universal. Rio de Janeiro, RJ: IBGE, 1991. 124p.

VOLPATO, G. H. Comunidades de aves em mosaico de habitat formado por Floresta Ombrófila Mista e plantações com Araucaria angustifolia e com Pinus elliottii, no sul do estado do Paraná, Brasil. 2009. 58 f. Tese (Doutorado em Ciências Biológicas) - Universidade Federal do Paraná, Curitiba. 
VOLPATO, G. H.; PRADO, V. M.; ANJOS, L. What can tree plantations do for Forest birds in fragmented Forest landscapes? A case study in southern Brazil. Forest Ecology and Management, Amsterdam, n. 260, p. 1156-1163, 2010.
WINAGRASKI, E.; ROMANIUK, D. S.; MARCELINO, V. R. Amostragem da avifauna na Estação Ecológica de Fernandes Pinheiro utilizando redes-neblina. In: SEMANA DE INTEGRAÇÃO ENSINO, PESQUISA E EXTENSÃO, 2., 2011, Irati, PR. Anais... Guarapuava: UNICENTRO, 2011. 
